\title{
Responsabilidades, cuidado e democracia
}

\author{
Responsabilities, care and democracy
}

A necessidade de cuidado pode ser pensada como parte do cotidiano das pessoas. As formas e a intensidade desse cuidado variam porque somos mais vulneráveis em alguns momentos da vida, como a infância e a velhice, e porque somos desigualmente vulneráveis durante a vida adulta, devido a condições físicas especiais, a enfermidades e à vulnerabilidade social. Coletiva e individualmente, não se trata de um tipo de problema passageiro, que possa ser simplesmente eliminado: não é possível suspender a dependência do cuidado de outros, embora esse fato possa ser significado e organizado de formas profundamente diversas. A disponibilidade e os padrões de distribuição de recursos materiais e tecnológicos, por exemplo, incidem no cuidado das crianças e nas formas que a vulnerabilidade e mesmo o sofrimento podem assumir em condições de doença e na velhice. Os recursos disponíveis para o suporte aos indivíduos são, assim, um dos aspectos que fazem com que momentos e condições de vulnerabilidade sejam vividos de maneiras diferentes pelos indivíduos. O cuidado envolve, além disso, relações interpessoais, independentemente de ser realizado por pessoas com quem se tem laços anteriores ou afetivos.

\footnotetext{
*É professora do Instituto de Ciência Política da Universidade de Brasília (Brasília, DF), onde integra o Grupo de Pesquisas sobre Democracia e Desigualdades (Demodê), e pesquisadora do CNPq. E-mail: flaviabiroli@gmail.com. As análises aqui apresentadas foram desenvolvidas no âmbito da pesquisa "Divisão sexual do trabalho e os limites da democracia: elaborações teóricas a partir das desigualdades de gênero no Brasil contemporâneo"(CNPq, PQ).
} 
Se o cuidado é um fato no cotidiano das pessoas, e um elemento organizador das suas relações, está longe de ser um tema com alguma centralidade nos estudos teóricos e empíricos sobre a democracia. No Brasil, é um tema pouco presente, sobretudo na Ciência Política, embora algumas pesquisadoras, mais frequentemente das áreas de Sociologia e Antropologia, venham se dedicando sistematicamente a compreender as articulações entre gênero, cuidado e família e entre gênero, cuidado e trabalho ${ }^{1}$.

Neste artigo, discuto as conexões entre cuidado e democracia. Entendo que a tematização e compreensão de como se estabelecem é incontornável para a teoria e para a prática da democracia, caso tenham como referência a possibilidade de construção de relações e formas de participação mais igualitárias na sociedade. A configuração das relações de cuidado é, como argumento aqui, determinante das possibilidades de acesso a recursos e à participação política. É, também, um fator na organização das relações afetivas e de solidariedade. Em seus padrões atuais, o cuidado privatizado e mercantilizado contribui para a reprodução de desigualdades e injustiças.

Entendo que a discrepância entre a centralidade do cuidado como problema no cotidiano das pessoas e nas teorias e estudos empíricos da democracia se deve ao predomínio de concepções restritas da política. Nelas, o impacto das desigualdades sociais para a democracia é pouco tematizado. Há, também, uma grande distância entre os fenômenos e espaços considerados para a análise da democracia e as experiências cotidianas das pessoas - e podemos pensar que essa distância se acentua quando se trata das experiências dos grupos que têm menor acesso às arenas políticas institucionais, algo que é parte da discussão apresentada neste artigo. A análise dos padrões diferenciados de participação política, por exemplo, se faz de forma restrita quando não leva em conta as determinantes cotidianas para o acesso a tempo, recursos e redes de contato, assim como os processos cotidianos em que a ambição e a vontade de participar da política são produzidas. As relações cotidianas de cuidado são determinantes da posição social relativa das pessoas, com impacto direto para as formas que sua participação na vida social assume, mas também para a possibilidade de que usufruam condições dignas de vida² .

Vale conferir a coletânea sobre cuidado e cuidadoras organizada por Helena Hirata e Nadya Araujo Guimarães (2012), e também o trabalho de autoras como Araújo e Scalon (2006), Hirata (2014) e Sorj (2013), entre outras.

Essa dignidade, no sentido aqui mobilizado, inclui acesso a recursos básicos e garantias para a integridade física e psíquica dos indivíduos. 
As teorias feministas da democracia se diferenciam de outras correntes teóricas na sua atenção às relações cotidianas de cuidado. Entendo que isso se dá não apenas pela maior visibilidade da posição das mulheres, que são, nos arranjos correntes, as principais responsáveis pelo cuidado e, justamente por isso, as mais afetadas pela desvalorização social do trabalho de cuidar. $\mathrm{Na}$ análise das formas históricas da exclusão e da marginalização das mulheres nas sociedades ocidentais, a crítica feminista estabeleceu duas perspectivas fundamentais para a análise dos limites da democracia: uma delas é a crítica à dualidade entre as esferas pública e privada, que permitiu que a segunda fosse entendida como natural, pré-política e, portanto, aquém dos requisitos de justiça e do tipo de igualdade pressuposta pela democracia; a segunda, bastante conectada à primeira, é a crítica à autonomização da política em relação às experiências e formas de dominação e de opressão cotidianas. A saliência das relações de cuidado como problema para a democracia se define ancorada nessas duas críticas fundamentais.

Para ser fiel a elas, de modo que o problema do cuidado seja conectado às relações de poder no cotidiano das democracias contemporâneas, parece-me adequado entender o cuidado como trabalho - sem que isso signifique que se trata de qualquer tipo de trabalho. Dissociar cuidado e trabalho pode ter o efeito de suspender as condições estruturais em que o exercício do cuidado, assim como a possibilidade de receber cuidado, se definem. Tanto de uma perspectiva de gênero como de uma perspeciva de classe ou de raça ${ }^{3}$, a divisão do trabalho implica a responsabilização diferenciada pelo cuidado. A orientação aqui presente se aproxima, assim, à de Pascale Molinier (2014, p. 32) quando diz que a posição feminista na abordagem do cuidado se distancia de uma visão estereotipada do feminino como conciliação, mas apresenta "uma alternativa na qual não ganham todos". Nesse sentido, neste artigo a colocação do cuidado no centro dos problemas da democracia é,

\footnotetext{
A raça é uma variável importante na definição dessas relações. Devo, no entanto, reconhecer que neste artigo aparece conectada à classe, mais do que discutida em suas especificidades. É como parte do grupo de mulheres mais pobres da população que as mulheres negras se encontram na posição de realizar trabalho doméstico remunerado, trabalho de cuidar de crianças e idosos, e de exercer trabalho em condições precarizadas - sem carteira assinada, por exemplo, como será discutido adiante. Isso não significa que os obstáculos ao exercício de ocupações de maior remuneração e de direitos trabalhistas incidam da mesma forma na vida das mulheres negras e das mulheres brancas. Sua condição no exercício do trabalho doméstico e de cuidado pode ser, também, diferenciada pelo fato de serem negras ou brancas. Deixo aqui anotado esse entendimento, embora assuma que seja pouco desenvolvido nas análises aqui apresentadas.
} 
como define Molinier, "indissociável de uma utopia política que coloca a divisão do trabalho no centro" das suas preocupações. Nela, "alguns e algumas devem aceitar o risco de perder privilégios" (p. 32) uma vez que as assimetrias que organizam as relações de cuidado estão sendo colocadas em questão. Nessa perspectiva, "o bem-estar de uns não pode repousar sobre a servidão de outros" (p. 20).

$\mathrm{O}$ artigo está organizado em três seções, precedidas por esta introdução e complementadas por uma breve conclusão. O caminho para a construção dos problemas é de certo modo longo porque faço a opção por discutir, ainda que rapidamente, a diferença entre abordar a responsabilidade individual e tratar da responsabilização como problema político. Por isso, a primeira seção do artigo discute brevemente os sentidos que a noção de responsabilidade vem assumindo no pensamento liberal, indicando deslocamentos que são provocados por análises atentas aos padrões estruturais das desigualdades. A manutenção ou questionamento da dualidade entre esfera pública e privada tem implicação nas relações que se tornam visíveis, nas formas de dependência que são consideradas e no modo como a responsabilidade é significada. Os problemas relacionados à responsabilização desigual dos indivíduos na vida cotidiana emergem dos questionamentos dessa dualidade. A atribuição das responsabilidades, incluídas aquelas que se organizam na esfera doméstica, pode ser assim discutida como questão política, com implicações para a democracia.

Na segunda seção, discuto a divisão sexual do trabalho como fundamento de formas diferenciadas e desiguais de responsabilização, com implicações para a participação das mulheres na sociedade, sobretudo das mais pobres. A análise das convergências entre as desigualdades de gênero e de classe expõe as implicações dos padrões correntes de responsabilização para a democracia, em que não apenas os papeis convencionais de gênero mas também os imperativos de mercado são definidores das posições. Por fim, a terceira seção discute mais diretamente o cuidado como questão de primeira ordem para a democracia. Explora alternativas tendo em mente a prevalência do mercado, a de soluções coletivistas e/ou a de soluções convencionalistas, entre as quais são destacados criticamente os apologistas da família e da domesticidade. Procuro, na análise, dar passos na consolidação de uma perspectiva que seja sensível a exigências fortes, articuladas, de democracia e de justiça. 


\section{Do indivíduo responsável à responsabilização como problema}

A noção de autonomia individual é peça-chave do pensamento liberal. Embora existam diferenças entre as abordagens no liberalismo, para a discussão feita neste artigo é importante o fato de que é nessa tradição de pensamento que toma forma, na modernidade, a noção de autonomia como autodeterminação. A associação entre a agência moral e a capacidade dos indivíduos de determinar seus próprios fins é importante na concepção kantiana da autonomia (Guyer, 2003). Nos debates contemporâneos, convive com outra herança, a da definição da liberdade como a possibilidade de que os indivíduos persigam seu próprio bem à sua maneira, desde que não tentem privar os demais das suas liberdades (Mill, 2008 [1859]). Nela, é resguardado um âmbito para a individualidade na medida em que são definidos limites à ação do Estado e das maiorias. O que está sendo afirmado nessas compreensões é mais do que uma qualificação para uma forma pré-existente da individualidade: elas participam da construção do indivíduo moderno. A pluralidade de crenças e valores em sociedades que se complexificavam e a igual capacidade dos indivíduos, como agentes morais racionais, para refletir sobre sua vida e seus objetivos são, assim, tomadas como pontos de partida e transpostas em normas e instituições nas quais a liberdade individual prevaleceria como valor de referência.

O pensamento liberal contemporâneo, herdeiro dessas concepções, apresentaria variações significativas na definição dos sentidos da justiça e dos requisitos para se garantir as liberdades individuais. Entre ultraliberais como Milton Friedman, Friederich Hayek e Robert Nozick e liberais igualitários como John Rawls há uma enorme distância. A centralidade do indivíduo está presente em todos esses autores, mas a conexão entre liberdade, escolhas individuais e responsabilidade, que é o que interessa de fato neste artigo, se organiza de maneiras distintas. As implicações não são menores: enquanto nos primeiros a ênfase nos projetos individuais inclui a valorização do mérito, permitindo assim justificar as desigualdades entre os indivíduos, no último mérito e talento devem ser suspensos como critérios para que exista justiça e ações distributivas do Estado são (sobretudo para o Rawls de Uma teoria da justiça) consideradas legítimas e necessárias.

A crítica ao mérito como critério para a justificação das desigualdades permite que as abordagens liberais igualitárias incorporem o fato de que as escolhas dos indivíduos não são feitas em contextos neutros. As trajetórias 
individuais são marcadas por fatos arbitrários e contingentes; a posição das pessoas, com seus atributos, não é em si justa ou injusta e não há razões para, portanto, aceitá-la como tal. O modo como as instituições lidam com esses fatos, por outro lado, pode ser justo ou injusto (Rawls, 1971, p. 102), o que implica uma compreensão de que instituições sensíveis às escolhas individuais são capazes de suspender ou amenizar arbitrariedades e contingências e, com isso, garantir a igual liberdade dos indivíduos. As desigualdades de partida, que impedem que as oportunidades sejam distribuídas equitativamente, deveriam ser suspensas para que possa existir, de fato, igual liberdade de escolha.

Os pressupostos presentes nas abordagens dos ultraliberais foram e são mobilizados, por sua vez, para compor argumentos contrários às políticas distributivas que caracterizam o welfare state, expondo a relação entre as posições nos debates nas ciências sociais e econômicas e as posições nas disputas políticas em torno da definição do âmbito da ação do Estado. É nessa frente das elaborações que a noção de autonomia ganharia de fato o sentido de "ser capaz de dar conta de si mesmo" e é também nela que se percebe mais claramente o reforço recíproco entre posições teóricas e posições políticas favoráveis à redução da presença do Estado nas sociedades capitalistas contemporâneas. Isso se deu, especialmente, no que concerne à divisão das responsabilidades entre governo, corporações/ agentes financeiros privados e indivíduos ou famílias. A precariedade que define a vida de muitos indivíduos impõe algum tipo de responsabilidade coletiva ou, vista como derivada de sua incapacidade e falta de talento, diz respeito apenas a eles?

Entre liberais igualitários como John Rawls, o esforço para que liberdade e equanimidade sejam articuladas na construção da justiça envolve, diferentemente, a contenção dos impactos injustos do mercado e das vantagens cumulativas nas sociedades capitalistas, abrindo um conjunto amplo de frentes para a crítica aos padrões finais desiguais nessas sociedades (Young, 2006). A recusa à correspondência entre talento e mérito para a justificação das desigualdades é um de seus aspectos, como dito anteriormente. O mérito pressupõe a existência de um sistema cooperativo, depende amplamente de circunstâncias sociais e familiares favoráveis - e por elas o indivíduo não pode requerer crédito (Rawls, 1971, 103-4). A relação entre talento e riqueza, por sua vez, elide o fato de que ela pressupõe "determinada estrutura econô- 
mica", uma estrutura de mercado que valide a relação entre riqueza-talento e a produção de riqueza (Dworkin, 2005 [2000], pp. 458-9).

Vale notar que as abordagens distributivas que assim se definiram não abriram mão da noção de responsabilidade pessoal nem fizeram uma crítica das estruturas básicas de concentração de riquezas e poder na sociedade capitalista - a propriedade privada permanece intocada e pouco é dito sobre as assimetrias no exercício da influência nas democracias capitalistas, em especial nas vertentes das teorias liberais da justiça que vêm sendo denominadas de igualitarismo de fortuna (para diferentes análises dessa vertente, conferir Anderson, 1999; Miguel, 2014; Scheffler, 2003; Vita, 2011; Young, 2011)5. Em sua ênfase na responsabilidade pessoal, as respostas dessas abordagens igualitárias ao libertarianismo e ao conservadorismo de direita oscilaram entre um contraste moralista entre responsáveis e irresponsáveis, ou independentes e dependentes, e uma visão paternalista dos "desafortunados" (Anderson, 1999, p. 23).

Em outro lugar (Biroli, 2013), discuti os limites dessas abordagens focando: (1) na suspensão das relações que dão sentido às escolhas individuais, que estão na base da própria identidade individual, o que permite criar uma ficção na qual os indivíduos precederiam e teriam exterioridade em relação a suas preferências e projetos (Sandel, 1998 [1982]); (2) na construção de uma ficção, a de que a ausência de constrangimentos no momento da escolha permite defini-la como voluntária, independentemente das assimetrias na produção das alternativas que estão dispostas e das condições desiguais em que se adere a uma ou a outra (Pateman, 1988; Young, 2006 e 2011); e (3) na suspensão da dinâmica social de produção das preferências ao derivar da livre-escolha dos indivíduos o grau de liberdade de que usufruem na gestão das suas próprias vidas (Miguel, 2014; Sunstein, 2009 [1991] e 2014).

4 Não há razões para pressupor que as riquezas-talentos sejam virtudes, segundo Dworkin. Afinal, a sorte é a mais importante entre elas, "estar no lugar certo é quase sempre mais importante do que qualquer outra coisa". E ainda que as riquezas-talento fossem virtudes, disso não decorre que deva haver recompensa material para elas. E mesmo que assim fosse, não há justificativa plausível para que o mercado comercial fosse a forma mais adequada de gerar essas recompensas (Dworkin, 2005 [2000], pp. 460-1).

Elizabeth Anderson situa nessa vertente Richard Arneson, Gerald Cohen, Ronald Dworkin, Thomas Nagel, Eric Rakowski e John E. Roemer, indicando também a incorporação de muitos dos seus princípios por Philippe Van Parijs. Na sua definição,"o igualitarismo de fortuna se ancora em duas premissas morais: que as pessoas devem ser compensadas pela má-sorte imerecida e que essa compensação deve vir somente da parte da boa sorte dos outros que é imerecida" (Anderson, 1999, p. 5). 
Para a análise que faço aqui, o ponto principal é a dualidade entre esfera pública e privada. Quando essa dualidade não é problematizada, a ação meritória dos indivíduos na esfera pública pode ser apresentada como distinta e independente das relações estruturadas na esfera privada e que dão condições para (ou impedem) que sejam sujeitos das suas vidas. Em modelos teóricos nos quais a esfera pública é autonomizada em relação à privada, essas relações podem não ser computadas na compreensão de como os indivíduos se tornaram quem são. Penso aqui no privado reivindicado como o âmbito das relações econômicas de mercado e também como o âmbito da vida doméstica e familiar. Nesse artigo, embora as relações de trabalho na vida doméstica recebam destaque, o foco é justamente na compreensão de como as estruturas de autoridade e as assimetrias presentes em cada um desses âmbitos incide sobre o outro e organiza as posições na esfera pública.

Entre os ultraliberais, a visão de que o mercado regula as relações de forma justa quando garante aos indivíduos a liberdade de escolher - ainda que em condições bastante desiguais - apaga as estruturas de autoridade e a dinâmica social de acúmulo de privilégios. O funcionamento do mercado não é neutro, premia quem já tem recursos para exercer influência sobre sua regulação e sobre os termos em que se organiza. Como define Martha McCluskey (2003, apud Tronto, 2013, p. 40), o que está em questão é "quais habilidades das pessoas para conseguir mais daquilo que elas buscam ao deslocar os custos para outras deveriam contar como ganho societário, e quais deveriam contar como ganho privado às custas de outras pessoas". Essa dinâmica permite que os privilegiados se apresentem como tendo construído sua posição por mérito próprio, apagando o fato de que ela é dependente da exploração do trabalho de outros e da ação favorável do Estado e de organismos capazes de fazer que a economia política gire a seu favor. O mérito também só se define como tal devido à valorização social de certas habilidades - o que se dá em processos históricos e ganha formas institucionais.

Entre as abordagens liberais nas quais existe real preocupação com a impacto de desigualdades e deficiências sobre a liberdade dos indivíduos para definir suas vidas, em que seu acesso a oportunidades é o aspecto fundamental, a dualidade entre público e privado permanece restringindo as críticas e as alternativas. Em John Rawls, por exemplo, a compreensão de que os critérios de justiça se aplicam à esfera pública mas são desnecessários às associações privadas nas quais a pessoalidade e os afetos prevaleceriam 
faz desaparecer um conjunto amplo de relações e experiências (Okin, 1989) e, principalmente, apaga as conexões entre as relações de poder na esfera privada e na esfera pública. A crítica à suspensão da vida doméstica e familiar como âmbito ao qual se aplicariam critérios de justiça tem sido, no feminismo, um dos pilares para a análise dos limites das concepções liberais em sua abordagem dos fundamentos dos privilégios dos homens em sociedades nas quais permanecem desigualdades de gênero significativas (Biroli, 2013; Miguel e Biroli, 2014).

As estruturas de autoridade nas relações de trabalho e na vida doméstica têm impacto na participação dos indivíduos em outras esferas da vida. Suas escolhas, por outro lado, não se definem na esfera privada ou na esfera pública, mas em contextos nos quais suas vidas são organizadas segundo o papel desempenhado em uma e outra. As alternativas disponíveis, o horizonte das possibilidades consideradas pelos indivíduos, assim como os recursos que permitem levar em consideração uma ou outra possibilidade se definem tendo como base a configuração dessas esferas - o modo como são delimitadas, mas principalmente a maneira como a organização de uma delas tem impacto sobre a outra. Embora essa seja uma questão discutida sistematicamente há décadas no feminismo, ela não foi de fato incorporada em grande parte do debate sobre justiça e sobre democracia.

A atenção às relações de poder na vida privada e doméstica permite a análise de estruturas de autoridade que são ao mesmo tempo distintas e complementares. Um dos efeitos da configuração dual dessas esferas é que a universalidade dos direitos (na esfera pública) se acomoda a distinções, divisões e hierarquias (na esfera privada), sem que isso apareça como um problema para a democracia. Enquanto a cidadania é definida como independência, "a dependência da sociedade como um todo, da economia e do sistema político relativamente à família e ao trabalho das mulheres na família é ignorada" (Brenner, 2000, p. 103).

As preferências dos indivíduos por determinadas formas de relacionamento e de organização da vida doméstica, assim como as escolhas nelas baseadas, têm relação direta com aspectos estruturais, nos quais fatores materiais e simbólicos convergem na produção de posições diferenciadas e desiguais. A fusão entre domesticidade e femininidade teve um papel histórico importante na naturalização da divisão sexual do trabalho. Ela permanece na base da socialização diferenciada de mulheres e homens e 
dos julgamentos socialmente ativos sobre os comportamentos de umas e de outros. Quando não se leva em conta essa configuração das relações, o foco nas escolhas individuais e na responsabilidade que os indivíduos têm por elas - mesmo quando se entende que é preciso equalizar sua posição na esfera pública (como em John Rawls) e que não é válido computar as arbitrariedades e contingências que restringiriam as oportunidades dos indivíduos ao avaliar suas condições (como em Ronald Dworkin) - nos afasta do entendimento de que o problema da responsabilização diferenciada é um fator na construção das alternativas dos indivíduos e das suas possibilidades de fazer escolhas "responsáveis".

O trabalho que as mulheres realizam na vida cotidiana doméstica, na sua forma e no tempo que é a ele dedicado, está longe de ser uma escolha voluntária, ainda que não seja assumido em situações que possam ser identificadas como de coação ou em contextos nos quais existam impedimentos legais para a busca de outros caminhos. Como compreender sua posição desigual na esfera doméstica e na esfera pública sem levar em conta que são orientadas a assumir determinadas responsabilidades e a desempenhar um conjunto de funções no cotidiano de modo que não configura nem escolha nem coação? Ao mesmo tempo, como dar conta dos obstáculos a uma participação equânime na vida pública se lançamos mão de uma moldura teórica que não permite compreender adequadamente as conexões entre a posição dos indivíduos na vida doméstica, com as responsabilidades diferenciadas que nela assumem, e os filtros que organizam sua posição em outras esferas da vida?

Nas sociedades ocidentais hoje, é possível considerar um cenário em que as mulheres não sejam controladas - coagidas - diretamente por homens específicos ao assumir toda, ou quase toda, a carga do trabalho doméstico, no qual incluo o trabalho necessário para o cuidado das crianças e de outros indivíduos que precisem, ou usufruam mesmo sem ser de fato dependentes, desse cuidado. Elas não são, por isso, excluídas da esfera pública. Parece-me adequado dissociar a exploração do seu trabalho de uma forma de domínio pelos homens que lhes são próximos que implicava a restrição da sua circulação na esfera pública. Diferentes tipos de ocupação estão abertos a elas no âmbito em que o trabalho remunerado se realiza, mas a exploração do seu trabalho na esfera doméstica permanece e pode ser compreendida como um dos fundamentos - entendo que o principal - da dominação de gênero. 
É nesse contexto de restrição às escolhas, constituído pelos padrões atuais da divisão sexual do trabalho, que se define não uma exclusão, mas formas desiguais de inclusão. O que se produz é um acesso desigual a ocupações, renda e tempo. A atribuição de responsabilidades diferenciadas a umas e a outros implica que o conjunto de problemas considerado ao "escolher" uma ocupação ou "estilo de vida" tem especificidades para elas. A escolha do casamento e a reprodução das formas convencionais da família, em condições que permanecem desvantajosas para as mulheres, pode ser explicada pela socialização mas também pelo ônus imposto quando as mulheres procuram construir suas vidas de outra formas. A difícil equação da necessidade de cuidado das crianças, por exemplo, e da necessidade de responsabilizar-se por si e por elas - sustentando a si e a elas, provendo condições mínimas para a vida cotidiana, como moradia e alimentação - tem impacto sobre as mulheres, pela divisão sexual do trabalho, e esse impacto se agudiza entre as camadas mais pobres da população, como será discutido na próxima seção.

\section{Divisão sexual do trabalho, responsabilização diferenciada e desigualdades}

A divisão sexual do trabalho doméstico e as desvantagens no mundo do trabalho são facetas complementares das desigualdades entre mulheres e homens hoje. Com todas as transformações que ocorreram nas últimas décadas, as mulheres continuam a dedicar muito mais tempo às tarefas domésticas e, por outro lado, a ter rendimentos bem menores do que os homens na esfera pública - embora no Brasil de hoje, acompanhando tendências verificadas também em outras partes do mundo, as mulheres tenham mais tempo de ensino formal que os homens e sejam a maior parte dos indivíduos que completam o ensino superior. As famílias não se organizam da mesma maneira que se organizavam poucas décadas antes, inclusive no que diz respeito à participação das mulheres na renda familiar, e os valores não permaneceram os mesmos, mas as mulheres continuam a ser as principais responsáveis pelo trabalho doméstico (C. Araújo e Scalon, 2006; Fontoura et alli 2010). Em 2013, enquanto $44,7 \%$ dos homens maiores de 10 anos de idade disseram realizar trabalho doméstico, esse número chegaria a $85,5 \%$ entre as mulheres. A discrepância é mais evidente quando se observa o número médio de horas semanais dedicados por eles e por elas ao trabalho doméstico, que foi no mesmo período de 10,4 horas semanais para eles e 23,8 horas semanais para 
elas (IPEA, 2014). Essa assimetria deve ser levada em conta para se explicar porque o rendimento médio mensal das mulheres foi, no mesmo ano, 30\% menor do que o dos homens - lembrando que o gap entre a renda média das mulheres brancas e das mulheres negras foi nesse período de $42 \%$ em favor das primeiras, ainda maior portanto do que aquele que existe entre homens e mulheres (IPEA, 2014).

Essas desigualdades são produzidas por uma divisão do trabalho que se ancora na naturalização de habilidades e pertencimentos de acordo com o sexo biológico. A associação entre mulher e domesticidade desempenha um papel ambivalente. Ela não correspondeu historicamente, e corresponde cada vez menos, à posição social efetiva de todas as mulheres nos países ocidentais. Mas ela funciona como dispositivo na alocação de responsabilidades - na vida privada, entre os indivíduos associados por laços familiares, afetivos e de convivência, mas também na esfera pública, nas normas que determinam ou favorecem uma certa divisão das responsabilidades entre Estado, famílias e indivíduos.

A domesticidade esteve, historicamente, ao alcance de poucas mulheres porque ela dependeu e depende de que a remuneração do homem, que vem ocupando convencionalmente a posição de chefe-de-família, seja equivalente a um "salário familiar". O homem provedor, de um lado, e a dona de casa, de outro, são personagens que têm, assim, classe social, posição nas relações de trabalho e cor bem definidas. Chamo a atenção, mais uma vez, para o fato de que embora o acesso das mulheres ao mercado de trabalho e a alternativa da domesticidade não tenham se definido de forma homogênea, a domesticidade tem tido uma função ideológica de sucesso: a naturalização da responsabilização prioritária das mulheres pelo trabalho doméstico e pelo cuidado dos familiares, especialmente das crianças. Como tal, atravessa diferentes classes sociais. Isso não significa que a vivência dos valores associados à domesticidade se dê da mesma maneira, mas que permanecem interpelando mulheres e homens a assumir papeis e estabelecer relações de formas distintas.

Assim compreendida, a associação entre o feminino e a domesticidade permanece como um dos fundamentos das desigualdades, organizando a divisão sexual do trabalho contemporaneamente. A posição das mulheres é hoje, nos países ocidentais, cada vez menos marcada pela reclusão, mas ainda profundamente marcada pela marginalização e inferiorização recorrentes das 
ocupações tipicamente "femininas", de menor remuneração e menor status, e do salário inferior ao dos homens nas mesmas funções, profissões e níveis educacionais (para o caso brasileiro, cf. Alves, 2013; A. Araújo e Lombardi, 2013; Bruschini, 2006; Bruschini e Lombardi, 2001 e 2002).

Podemos pensar em duas frentes para a interpretação dessas desigualdades. Numa delas, é destacada a permanência das relações de exploração na família, que é vista ao mesmo tempo como função da dominação masculina na esfera pública, em que os homens são os proprietários, controlam as forças produtivas e ocupam as posições políticas que lhes permitem regulá-las segundo seus interesses. É essa a posição de Christine Delphy e Diana Leonard (2004 [1992], p. 18) quando afirmam que "na família, na nossa sociedade, as mulheres são dominadas para que seu trabalho possa ser explorado e porque seu trabalho é explorado". Numa outra frente, Sylvia Walby (1990), na sua interpretação das formas atuais do patriarcado, que corresponderiam a deslocamentos do que define como "patriarcado privado" para o que define como "patriarcado público", ressalta as conexões entre novas estratégias de inclusão das mulheres e novas formas de controle sobre elas. Seu ponto é que quando diminui o grau em que as estruturas familiares patriarcais organizavam a exclusão das mulheres, sua segregação e sua posição desvantajosa são determinadas pela estrutura patriarcal do Estado e do mercado de trabalho: “elas não são barradas das arenas públicas, mas são ainda assim subordinadas nessas arenas" (Walby, 1990, p. 178).

Não pretendo aqui avançar na discussão, sem dúvida relevante, sobre como cada uma dessas interpretações situa a relação entre a dominação masculina (ou patriarcado) e o capitalismo. O que me parece central para este artigo é que nos dois casos, embora a ênfase na exploração e dominação na família seja diferenciada, o gênero permanece como fundamento da organização das relações de trabalho $e$ a divisão sexual do trabalho permanece definidora das desvantagens relativas das mulheres.

A relação entre trabalho doméstico não-remunerado, trabalho doméstico remunerado e o acesso a outras ocupações se define em um contexto em que a atribuição das responsabilidades pelo trabalho cotidiano de reprodução da vida permanece prioritariamente dirigida às mulheres. Embora existam diferenças importantes entre as atividades que são desempenhadas no cotidiano da vida doméstica, como cozinhar, lavar as roupas, limpar a casa, dar banho nas crianças, em deficientes ou idosos, auxiliar em atividades dessas 
mesmas pessoas que não poderiam se dar de maneira segura sem acompanhamento, como passeios em áreas públicas, ou desempenhar o que algumas autoras definem como trabalho emocional (Delphy e Leonard, 2004 [1992]; Hochschild, 2003 [1983]), é possível considerar que todas elas implicam envolvimento, tempo e energia de quem as realiza, sendo ou não passíveis de caracterização como trabalho produtivo. Todas elas implicam, também, quando se trata de mais do que o cuidado consigo mesma, que uma atividade está sendo realizada em prol e em vantagem de outras pessoas, ainda que isso signifique algo muito distinto se a vantagem é de um homem que usufrui desse trabalho sem nunca realizá-lo (alimenta-se, tem suas roupas e a casa onde vive limpas) ou de crianças, idosos ou pessoas deficientes que não poderiam realizá-lo (nesse caso, usufruem de tarefas que não seriam capazes de realizar, mas permanece o fato de que alguém dispende tempo e energia para seu cuidado - no mais das vezes, uma mulher, de acordo com os dados antes mencionados).

As relações que assim se estabelecem são distintas também caso se trate de trabalho doméstico não-remunerado ou remunerado. No primeiro caso, o gênero prevalece na alocação das tarefas e responsabilidades, enquanto no segundo classe e raça são também definidoras da distinção entre quem realiza o trabalho e quem pode pagar por ele e dele usufruir, ainda que, de novo, no mais das vezes sejam mulheres que o realizam.

As mulheres não estão igualmente distribuídas entre quem está na posição de provedor de cuidado, trabalhando no cuidado de outros, e quem está na posição de beneficiário do cuidado provido por outras pessoas (Brenner, 2000; Hirata, 2014; Tronto, 2013). Mas o gênero é fundamental à organização das relações de trabalho nas quais o cuidado toma forma. As mulheres estão concentradas em atividades vistas como extensão das atividades domésticas não remuneradas e, como tal, desvalorizadas e menos formalizadas. No ano de 2013, no Brasil, 18,6\% das mulheres negras e 10,6\% das mulheres brancas ocupavam emprego doméstico remunerado - no mesmo período, $1 \%$ dos homens negros e $0,7 \%$ dos brancos estavam nessa mesma posição (IPEA, 2014). Desde 2009, a Pesquisa Nacional por Amostra de Domicílios (PNAD) do IBGE mostrava uma queda lenta mas ininterrupta no número de mulheres que realizam trabalho doméstico remunerado. Em 2013, esse número era de 5.963.976, 11,6\% menor do que em 2009, quando era de 6.750.416. Mas essa tendência pode estar se revertendo - a PNAD Contínua 
divulgada pelo IBGE mostra que esse número ultrapassou novamente o de 6 milhões de mulheres empregadas em trabalho doméstico no primeiro trimestre de 2015. A redução no número de trabalhadoras domésticas podia ser interpretada como expressão de mudanças relacionadas à queda do desemprego, à maior escolarização e à redução da probreza na década de 2000 no Brasil ${ }^{6}$, aproximando o país das circunstâncias nas quais o trabalho doméstico remunerado diminui na Europa e nos Estados Unidos ao longo do século XX. Hoje, no entanto, a reversão dessa tendência, caso se confirme, é que nos colocaria em sintonia com o que ocorre nas regiões mais ricas do globo, nas quais o trabalho doméstico vem aumentando à custa do trabalho precarizado e mal-remunerado de imigrantes não-europeus e provenientes das regiões da Europa mais afetadas pelo desemprego (Schwenken, 2005 e 2011; R. Sarti, 2006).

É um elemento importante para esta discussão o fato de que nos domicílios mais ricos, no Brasil (e ainda que em menor quantidade, também em países mais ricos do Ocidente, como mencionado há pouco), a divisão sexual do trabalho está presente mas as mulheres têm o apoio do trabalho de cuidadoras e empregadas domésticas, mal-remunerado e caracterizado por relações de exploração ainda mais acentuadas do que nas atividades vistas como produtivas e tipicamente desempenhadas pelos homens fora de casa (cf. Brites, 2007 e 2013). Em um contexto em que as mulheres de classe média estão cada vez mais presentes no mercado de trabalho, mas prevalece o entendimento de que as atividades de reprodução da vida são de responsabilidade das famílias como unidades privadas, o trabalho doméstico remunerado tem enorme importância. Sua centralidade está relacionada ao fato de que a oferta de serviços públicos é insuficiente (creches e escolas em período integral, por exemplo) e ao fato de que as alternativas coletivas à mercantilização dessas atividades são praticamente inexistentes (cozinhas coletivas e rodízio no cuidado com as crianças e outros indivíduos que necessitem de cuidado cotidiano, por exemplo).

Nas condições descritas, o trabalho doméstico é sem dúvida relevante e invisibilizá-lo vai na direção contrária do acesso a direitos, da valorização do

\footnotetext{
Vale observar que o número de trabalhadoras domésticas que residem no domicílio onde trabalham vem diminuindo continuamente desde 1999: naquele ano, elas eram $9 \%$ das trabalhadoas, em 2013 eram 1,9\% (IPEA, 2014). Este dado me parece significativo porque é justamente nos casos em que as trabalhadoras residem no local de trabalho que pode haver maior exploração e aproximação de condições de servilidade, sem definição clara das jornadas de trabalho e tarefas.
} 
trabalho e de quem o realiza. Mas dar visibilidade a esse trabalho significa também expor as condições nas quais se realiza (Hirata, 2011; Sorj, 2013). Em 2009, aproximadamente uma em cada quatro mulheres no emprego doméstico tinha carteira assinada e $0,5 \%$ delas, o que corresponde a cerca de 30 mil mulheres, não tinham renda própria, isto é, encontravam-se numa situação semelhante à de trabalho escravo (IPEA, 2011). Em 2013, ano em que foi aprovada pela primeira vez no Brasil legislação que equipara as trabalhadoras domésticas a outras/os trabalhadoras/es, apenas 31,8\% delas tinha carteira assinada - esse percentual fica abaixo dos $30 \%$ quando se considera apenas as mulheres negras e está abaixo dos $20 \%$ nas regiões Norte e Nordeste do país (IPEA, 2014).

Estamos tratando, portanto, de relações que são um produto e um fator na reprodução das desigualdades de classe e de raça, expressivas também das desigualdades em nível global. Por isso o trabalho doméstico remunerado tem sido definido como um problema em si para a democracia: o tipo de relação que assim se estabelece rompe com a igualdade que é necessária à democracia na medida em que cria subordinados, mas também mestres. Marca quem o exerce, ao mesmo tempo que reforça a identidade e o status social diferenciado de quem emprega (Tronto, 2013, p. 111). Nas condições em que é realizado, o trabalho doméstico remunerado corresponde a uma radicalização das hierarquias e formas de opressão presentes de forma mais ampla no mundo do trabalho.

Além de corresponder a hierarquias nas relações de trabalho, a alocação desigual das responsabilidades incide de maneira específica sobre as mulheres, e de maneira desigual para grupos diferentes de mulheres, como vem sendo dito. $\mathrm{O}$ acesso a tempo e posições no mundo do trabalho é bastante diferente para elas e para eles, como foi visto nos dados sobre tempo médio dedicado à realização de atividades domésticas e renda média de umas e outros. Pode-se também trabalhar com a hipótese de que é um fator importante no acesso desigual de mulheres e homens à participação política, sobretudo em cargos eletivos.

Embora não seja fácil estabelecer uma correspondência causal entre a responsabilização diferenciada de mulheres e homens pelo trabalho doméstico e sua baixa presença na política, é importante levar em conta que é nessas condições - que envolvem acesso diferenciado a tempo, a renda e a redes de contato e, por outro lado, custos maiores para perseguir uma 
carreira política (Miguel e Biroli, 2011, cap. 2) - que essa outra forma de desigualdade se define e se reproduz. No Brasil, a presença das mulheres na Câmara dos Deputados tem sido de no máximo 10\% das cadeiras; considerando-se as Assembleias Estaduais esse percentual muda pouco, as mulheres foram 11,3\% do total de parlamentares eleitos em 2014. Variáveis do próprio campo político devem ser também levadas em consideração, mas os estudos que buscam explicações para as desigualdades de gênero nesse âmbito têm mostrado que as práticas e valores que sustentam uma divisão sexual do trabalho fundada em concepções convencionais do feminino e do masculino têm impacto na participação das mulheres em todos os âmbitos da sociedade e na política em particular (C. Araújo e Alves, 2007; Miguel e Biroli, 2011) e que "a ausência da mulher na esfera política não pode ser posta unicamente na conta dos limites da democracia liberal", com o funcionamento seletivo de suas instituições e suas "limitações estruturais para incluir novos sujeitos" (Pinto, 2010, p. 22).

Menos presentes na esfera política, as mulheres têm menores condições de influenciar as decisões e a produção das normas que as afetam diretamente. Embora essa forma de exclusão não atinja apenas as mulheres, mas também boa parte dos homens - nesse sentido, o acesso às esferas políticas nas democracias contemporâneas mantém componentes censitários e raciais, ainda que isso não seja explícito -, a responsabilização diferenciada pelo trabalho doméstico e pelo cuidado das crianças e dos indivíduos mais vulneráveis impõem a elas obstáculos adicionais. Esse é um caso em que os filtros de classe (e os de raça) se combinam com aqueles que a divisão sexual do trabalho ativa, definindo obstáculos adicionais para a participação das mulheres mesmo dentro de um mesmo estrato socioeconômico.

Em outros aspectos, no Brasil são as mulheres negras, e não as mulheres de maneira geral, as mais impactadas. Os dados sobre pobreza (IPEA, 2014, a partir da base de dados do Programa Brasil Sem Miséria) mostram que 57,8\% dos homens e 59,1\% das mulheres encontravam-se em 2013 na faixa da população em situação de extrema pobreza, de pobreza e de vulnerabilidade (em todos os casos, com renda domiciliar inferior a um salário mínimo ${ }^{7}$ ). Ainda que essa

O Programa Brasil Sem Miséria trabalha com as seguintes variáveis e valores para o ano de 2013: extremamente pobres são indivíduos com renda domiciliar per capita de até $R \$ 79,12$; pobres são aqueles com renda domiciliar per capita maior ou igual a R\$ 79,12 e menor que R\$ 158,24; vulneráveis têm renda domiciliar per capita maior ou igual a R\$ 158,24 e menor que R\$678, valor do salário mínimo em 2013. Em todas as categorias, trata-se de indivíduos com renda domiciliar menor que um salário mínimo. 
diferença de 1,3\% seja significativa, a distância entre as mulheres brancas e as mulheres negras mostra clivagens bastante acentuadas, que não permitem que se conclua, a partir da posição de gênero, sobre a vulnerabilidade relativa das mulheres nesse quesito: entre as brancas, $45,9 \%$ estão em condição de extrema pobreza, pobreza e vulnerabilidade; entre as negras esse número chega a 70,9\%. Assim, no que diz respeito à pobreza, mais mulheres do que homens se encontram nos estratos mais pobres da população, mas as mulheres negras estão numa posição bem próxima da dos homens negros (68,4\% deles estão nessa condição) do que das mulheres brancas, que por sua vez têm uma posição bem próxima à dos homens brancos (44,9\% deles estão nessa condição). Os dados sobre renda e chefia familiar confirmam essa interpretação: a renda per capita média dos domicílios em que o chefe-de-família é homem é 12,3\% maior do que a daqueles chefiados por mulheres, nesse caso sem desagregação por cor (lembrando que é entre as famílias chefiadas por mulheres que se encontra o maior número de famílias sem cônjuges e com filhos, trazendo elementos que colaboram para compreender o que constrange a renda nesse caso). Quando são observados apenas os domicílios chefiados por mulheres, a renda per capita média daqueles chefiados por mulheres brancas é $90 \%$ maior do que a daqueles chefiados por mulheres negras (a partir dos dados disponíveis em IPEA, 2014). Em conjunto, esses dados parecem afastar a possibilidade de se compreender a vulnerabilidade e a pobreza como questões femininas, sem no entanto reduzir a necessidade de que sejam entendidos como algo que atinge de maneira direta determinadas mulheres.

A posição de maior vulnerabilidade das mulheres no casamento, que não se esgota nos aspectos socioeconômicos mas guarda relação estreita com eles, também pode ser associada a esse quadro mais amplo em que a divisão sexual do trabalho constitui desigualdades. A decisão de sair de um casamento pouco satisfatório tem custos diferenciados para mulheres e homens. É algo que se agudiza nos casos de violência doméstica - e que colabora para explicar porque muitas vezes as mulheres retornam para casas e relacionamentos, mesmo após terem sido agredidas e violentadas. Não é, assim, apenas a autonomia no sentido de independência econômica, com a capacidade de responsabilizar-se pela própria sobrevivência, que é mais difícil de ser alcançada para as mulheres do que para os homens. Sua integridade física e psíquica é potencialmente ameaçada pela situação de dependência produzida pelas desvantagens da divisão sexual do trabalho. É um quadro 
que se torna mais complexo quando se leva em consideração as crianças, que são por sua vez dependentes dos adultos - a opção das mulheres por manter um casamento pode se dar em função de escolhas que levam em conta a vulnerabilidade das crianças.

Apesar de todos esses aspectos, o papel reservado às mulheres na divisão convencional do trabalho não recebe apenas sinal negativo no feminismo. Em algumas abordagens, há um esforço para mostrar que há bem mais do que opressão nas atividades e experiências das mulheres na vida doméstica. Sua desvalorização é vista como um problema por colaborar para o silenciamento das experiências das mulheres, reduzindo sua relevância.

Para as autoras do pensamento maternal, também chamado de "ética do cuidado", a dualidade convencional entre o público e o privado colaborou para que temas e problemas que se definem a partir da posição dos indivíduos na esfera privada, entre eles o cuidado (ou a negligência) com as crianças, questões relativas à saúde, à sexualidade, aos direitos reprodutivos e à violência doméstica, fossem despolitizados e "construídos como meras expressões de valores pessoais e preocupações de caráter moral" (Elshtain, 1992, p. 113). Essa despolitização também excluiria da esfera pública valores e preocupações que seriam tipicamente femininos, dada a posição social das mulheres. A institucionalização do poder masculino teria correspondido, largamente, à incorporação de grande parte da vida social aos códigos e ao controle jurídico e burocratizado do Estado, com o estreitamento dos âmbitos nos quais o poder informal das mulheres teria sido historicamente exercido, o doméstico e o sagrado. O poder masculino - e a justiça - corresponderiam, assim, a um tipo de "progresso" no qual as mulheres representam "o pólo negativo juntamente com a natureza, a emoção e a paixão” (Elshtain, 1992, p. 116). Uma das críticas assim elaborada se dirige ao fato de que o pensamento moderno situaria os indivíduos em um mundo no qual "os indivíduos são adultos antes de terem nascido; os garotos são homens antes de terem sido crianças; um mundo no qual nem mãe, nem irmã, nem esposa existem" (Benhabib, 1987, p. 85). O acesso das mulheres à cidadania teria sido marcado, historicamente, pela confirmação desse apagamento: elas seriam cidadãs desde "que sua voz específica desse lugar ao discurso simbólico dominante" (Finzi, 1992, p. 139).

Na contramão, assim, de um mundo fundado na abstração de indivíduos racionais e isolados, seria importante, para as pensadoras do maternalismo, 
valorizar as experiências e perspectivas das mulheres, engendradas por sua posição na esfera privada. Um dos principais problemas é que a dualidade entre o público e o privado tem, nesses argumentos, seu sinal invertido, mas não há uma orientação sobre como seriam superados os obstáculos estruturais relacionados ao papel das mulheres na vida doméstica, de que falava até agora. Ainda que a importância do cuidado com as crianças, por exemplo, seja inquestionável, a experiência valorizada, nesse caso, é justamente aquela que resulta da domesticação, da segregação das mulheres à esfera privada e/ ou a atividades e competências consideradas femininas na esfera pública e que historicamente roubaram-lhe a voz.

É uma direção bem diferente da que assumo aqui, em que o problema está na privatização do cuidado e da vida familiar. A afirmação da maternidade individualizada e privatizada vai na direção oposta da criação de "instituições que dariam a todas as mulheres, e não apenas às ricas, a oportunidade de que seus filhos cresçam em ambientes saudáveis e alegres", que possam trabalhar "sabendo que seus filhos estarão bem nas mãos de cuidadores especializados nas creches, nas escolas ou em casas coletivas para crianças" (Kollontai, 1977, p. 146). A comparação entre as formas de realização da maternidade para mulheres de diferentes classes sociais mostra que a singularidade e os ideais da maternidade são acessíveis a poucas e que sua construção como questão privada colabora para que sejam mantidas as condições de injustiça em que a maternidade se realiza para a maioria das mulheres ${ }^{8}$.

A posição hierárquica da dona-de-casa e o trabalho doméstico desvalorizado são faces de uma mesma moeda, mesmo quando as mulheres trabalham dentro $e$ fora de casa. Entre as camadas mais pobres da população, a permanência da mulher na posição de "dona-de-casa" pode ser um efeito casado das convenções de gênero e do desemprego (Davis, 1983 [1981], p. 239), e não uma escolha que individualiza e dá sentido à vida. Mais uma vez, desvalorizar o trabalho que realizam nessas condições não parece ser a melhor forma de enfrentar a dinâmica de opressão ancorada na divisão sexual do trabalho.

\footnotetext{
A comparação feita por Alexandra Kollontai entre gravidez e maternagem de quatro mulheres, a esposa do diretor da fábrica, a lavadeira, a empregada doméstica e a trabalhadora da fábrica de tecidos é exemplar (Kollontai, 1977; pp. 127-139). Vale lembrar que na abordagem da autora a centralidade do trabalho é determinante tanto para evitar o gasto de energia em "trabalho improdutivo" quanto para garantir a saúde e produtividade das novas gerações (Kollontai, 1977, p. 142). Embora seja uma perspective marcada por um sentido específico da coletivização, ela joga luz sobre seu oposto, a privatização e seus efeitos.
} 
O esforço para realizar, simultaneamente, a crítica à opressão das mulheres na esfera doméstica e a crítica à desvalorização do trabalho doméstico cotidiano das mulheres, que seria "ao menos tão fundamentalmente construtor-do-mundo e produtor de sentido ${ }^{9}$ quanto o trabalho tipicamente masculino" (Young, 1997, p. 156), esbarra em pelo menos dois problemas. Um deles é que no mundo em que vivemos a cidadania e o reconhecimento social permanecem, em muitos sentidos, associados ao trabalho remunerado, que é também um dos canais para a construção das redes que dão acesso à política. Tomar parte da esfera pública por meio da inserção no mundo do trabalho em vez de permanecer na rotina de isolamento e trabalho doméstico repetitivo é considerado por muitas delas um bem, mesmo quando o trabalho fora de casa está muito distante da autonomia e das condições cotidianas e de remuneração que se poderia desejar (Davis, 1983 [1981], p. 242). Considerada a dinâmica do trabalho doméstico, a gratificação pode estar em "pelo menos, sair de casa", "pegar aquele ônibus e ver todo aquele movimento", como aparece em um dos depoimentos de mulheres da periferia da cidade de São Paulo apresentados por Cynthia Sarti (2011, p. 100), ainda que outros depoimentos relatem o sentido de dignidade da casa limpa e arrumada e dos filhos bem cuidados (C. Sarti, 2011, p. 99), confirmando formas de valorização e de julgamento implícitas na divisão convencional dos papéis.

A suspensão da divisão sexual do trabalho como problema nos levaria de volta às compreensões limitadas da responsabilidade e da independência que foram discutidas na primeira seção: tomar os indivíduos abstratamente, como se seu cotidiano não fosse marcado pelas formas diferentes de responsabilização que estão no cerne da organização cotidiana da vida nas sociedades contemporâneas, é impor a eles (a elas, nesse caso) um ônus a mais, o de se posicionar como iguais - igualmente independentes, sobretudo - em condições adversas. A divisão sexual do trabalho implica desvantagens específicas para que as mulheres tomem parte da esfera pública e do mundo do trabalho como iguais, o que por sua vez as torna potencialmente mais vulneráveis, como dito. A abordagem dessa situação, mesmo quando se reconhece que se trata de injustiças que organizam as escolhas possíveis para os indivíduos, em vez de serem delas derivadas, pode reafirmar convenções

No original, world-making and meaning-giving. 
que naturalizam a divisão sexual do trabalho ou confrontá-las. É também aí que se desenha a "linha fina mas muito importante", segundo a formulação de Johanna Brenner (2000, p. 108), "entre a demanda feminista de que os homens se responsabilizem por suas crianças e a demanda anti-feminista de que os homens tenham a obrigação de ser os provedores da família”, que viria associada ao entendimento de que a pobreza e a vulnerabilidade de mulheres e crianças derivariam das separações e mudanças nas relações familiares, indicando como remédio portanto a afirmação da família nuclear convencional. Brenner está tratando do contexto estadunidense, mas essa construção do problema me parece relevante quando se pensa no caso brasileiro, em que vem crescendo a defesa conservadora da família, nas suas formas convencionais (Biroli, 2014).

Uma teoria democrática que seja capaz de lidar com essas desigualdades, em vez de simplesmente suspendê-las como questões para a democracia e para a justiça, precisará necessariamente dar conta da ambivalência que marca a ideia de reconhecer o valor do trabalho realizado pelas mulheres no cotidiano da vida doméstica. O mesmo tipo de ambivalência se apresenta quando afirmamos a necessidade de reconhecer que o cuidado, que neste artigo está sendo compreendido como parte - ainda que singular - do trabalho cotidiano na esfera doméstica, tem importância incontornável para que o ideal de igual dignidade tenha sentido de fato nas democracias. Quem se responsabiliza pelo cuidado e que formas ele assume são questões fundamentais: dependendo da resposta, poderemos nos afastar ou nos aproximar de um ideal democrático no qual a tolerância à subordinação de parte dos indivíduos não tenha lugar.

\section{Cuidado, dependência e democracia}

Parte do trabalho realizado no cotidiano da vida doméstica, e que tem sido largamente de responsabilidade das mulheres (sendo ele remunerado ou não), consiste em atividades que têm como objetivo atender necessidades de cuidado que são incontornáveis. É o que ocorre sobretudo quando se pensa no cuidado das crianças, dos idosos, dos portadores de deficiências e doenças crônicas, assim como das mais diversas pessoas quando adoecem. Não se trata, assim, de algo que possa ser superado. Por isso, negar o cuidado como parte da vida não corresponde simplesmente a uma ilusão, é algo que tem efeitos perniciosos porque reduz nossa capacidade de encontrar solu- 
ções que sejam sensíveis à realidade múltipla e diferenciada das pessoas que precisam de cuidado e à situação específica de quem trabalha para atender a essas necessidades. $\mathrm{O}$ desafio se amplia porque respostas pontuais à primeira (à realidade de quem precisa de cuidado), como aquelas que a mercantilização do cuidado provê, poderão excluir um grande contingente de pessoas e não serão, necessariamente, capazes de incluir garantias de que aquelas que exercem o trabalho de cuidar não terão ampliada sua vulnerabilidade social pelo fato de estarem nessa posição. "Somos todos provedores e beneficiários de care [sic] e, todos, dependentes" (Molinier, 2012, p. 41), mas, dada a configuração atual, alguns têm maiores chances de receber cuidado, enquanto outras têm sua condição marcada negativamente pelo exercício do cuidado, em suas formas não-remuneradas e remuneradas.

Quando se rompe com a invisibilidade do complexo de relações de que estamos tratando ao falar de cuidado, invisibilidade esta que é característica da maior parte do debate sobre democracia, a dependência aparece como realidade da vida cotidiana. Mais uma vez, temos aqui um exemplo de como o debate sobre democracia pode se afastar do cotidiano das pessoas: é nele, e certamente não na experiência vivida das pessoas, que a dependência e as demandas por cuidado podem ser suspensas como questões de primeira ordem. Em sua ampla maioria, "as teorias políticas democráticas assumem a existência de atores autônomos como ponto de partida para a democracia” (Tronto, 2013, p. 31), o que impede que se leve em consideração a dependência e o trabalho realizado cotidianamente face a ela. Com isso, fica reduzida, como dito anteriormente, nossa capacidade de encontrar soluções satisfatórias para equilibrar autonomia e dependência.

Duas autoras têm suas abordagens consideradas como fundamentos do debate sobre cuidado hoje. A partir do trabalho de Carol Gilligan, ganharia forma uma vertente que define as relações de cuidado como a base para uma ética diferenciada. Embora Gilligan seja específica na definição da sua posição, esclarecendo que a "voz diferenciada" das mulheres não emerge da condição feminina mas de experiências decorrentes de sua posição social, essa abordagem tem permitido aproximações entre cuidado e feminilidade. A segunda autora é Joan Tronto, que estabelece um diálogo crítico com a análise feita por Gilligan e amplia a discussão ao situar o cuidado como questão prioritária para a democracia. Embora a contribuição de Gilligan para a análise da exclusão das vozes e experiências das mulheres tenha sido impor- 
tante, ela teria favorecido o entendimento de que existe uma correspondência entre diferenças de gênero e diferentes perspectivas morais - e, assim, entre o cuidado e a feminilidade (Joan Tronto, 1987, p. 646). Os riscos, tais como enunciados por Tronto, estariam na marcação negativa do cuidado, numa sociedade em que o masculino corresponde à normalidade e o feminino carrega o sentido da inferioridade, mas estaria também numa armadilha, a de que a defesa da centralidade do cuidado (de uma "ética do cuidado", nas palavras da autora no texto a que me refiro aqui) implicaria a defesa de uma moralidade feminina. $\mathrm{O}$ ponto de Tronto nos leva de volta à ambivalência antes mencionada: a valorização do cuidado não pode suspender a crítica ao fato de que nas sociedades modernas sua definição como uma ética diferenciada deriva das condições de subordinação das mulheres (Tronto, 1987, pp. 646-7). As diferenças, portanto, remetem não ao fato de se tratar de mulheres ou de homens, mas ao papel desempenhado (Tronto, 1987, p. 652): quem tem a experiência do cuidado, quem assume a responsabilidade de cuidar, terá uma perspectiva diferente do que são as relações cotidianas e do que importa. É isso que permitiria, ainda segundo Tronto (1987) que alguns indivíduos e grupos (ela menciona comunidades negras e latinas nos Estados Unidos) tenham potencialmente uma posição que leva a um maior desenvolvimento de parâmetros éticos e morais centrados no cuidado.

Para os argumentos que sustento aqui, o mais importante é que a responsabilização diferenciada implica um contato também distinto com a dependência e os custos, mas também sentimentos, que cuidar implica. Entre o artigo antes mencionado, publicado em 1987, e seu livro publicado mais recentemente, em 2013, Joan Tronto avança na construção de uma teoria democrática do cuidado ao confrontar mais diretamente duas questões: as assimetrias e desigualdades sociais que a configuração (de gênero, classe e raça) das relações de cuidado assume nas sociedades contemporâneas e os limites que a mercantilização impõe.

Uma vez que as relações de cuidado ganham centralidade, torna-se difícil trabalhar com a dualidade entre dependência e independência como se expressasse o resultado de escolhas menos ou mais responsáveis ou, ainda, como uma espécie de menoridade (biológica ou moral) a ser transposta. Mesmo no âmbito do feminismo, a perspectiva liberal de que as mulheres serão libertadas da opressão do trabalho doméstico e alcançarão uma situação de igualdade relativamente aos homens pelo acesso ao trabalho remunerado 
é uma idealização baseada na vivência das poucas mulheres que podem ter acesso a carreiras profissionais com grau relativamente ampliado de autonomia e de remuneração (Hooks, 1984, p. 61). Mantidos os arranjos atuais, isso significa que o trabalho doméstico e de cuidado está sendo transferido a outras mulheres, as quais por sua vez terão maiores dificuldades para transferir a outras pessoas o trabalho cotidiano que sua própria vida e o cuidado dos que lhes são próximos envolve ${ }^{10}$.

Essa alocação desigual não é aleatória, mas atende a padrões que têm correspondência com as hierarquias de gênero, raça e classe social. Entre os que cuidam, há mais mulheres, mais negras/os e mais indivíduos das camadas mais pobres da população. Entre os que recebem cuidado mais intensivo (pelo tempo e atenção a eles dirigidos) e mais qualificado (em termos da capacitação de quem o exerce e dos recursos materiais disponíveis para seu exercício) estão mais homens, mais brancas/os e mais indivíduos das camadas mais ricas da população.

A invisibilização das tarefas alocadas está, assim, diretamente relacionada a quem as exerce ${ }^{11}$. Por serem assumidas por quem está em condição

10 Relatos de mulheres brasileiras de baixa renda que têm filhos mostram que enfrentam cotidianamente uma situação em que, pela falta de creches ou de horários compatíveis de creches e escolas com as rotinas de trabalho que Ihes são exigidas, deixam seus filhos com familiares - outras mulheres já aposentadas ou que têm dificuldades para conseguir trabalho remunerado por terem elas mesmas filhos pequenos - ou com mulheres jovens a quem contratam pagando uma parcela de seus salários, uma cadeia em que o trabalho doméstico recebe remuneração menor e é mais precário quanto mais próximo está de arranjos entre pessoas das camadas mais pobres da população. O pagamento de creches ou cuidadoras por mães trabalhadoras pode comprometer parte significativa de seu salário. Somada às dificuldades cotidianas para acomodarem a rotina de trabalho e a rotina doméstica, essa é uma das razões pelas quais muitas dessas mulheres podem deixar de trabalhar, contando com o recurso de companheiros e outros familiares quando isso é possível (Folha de S. Paulo, Thais Bilenky, "Sem creches de Haddad, mães improvisam na volta às aulas em São Paulo, publicada em 2 de fevereiro de 2015). Existe uma correlação entre o nível de ocupação das mulheres e a frequência dos filhos pequenos a creche: esse nível é de $65,4 \%$ para mulheres com filhos de 0 a 3 anos de frequentam creche, de 40,3\% se apenas algum filho frequenta a creche e de 41,2\% para aquelas cujos filhos não frequentam creches (IBGE, 2014).

11 Helena Hirata (2014, p. 67) aponta para dois caminhos diferentes na compreensão da desvalorização social do trabalho de cuidado. Um deles, predominante no feminismo, é que por ser extensão do trabalho doméstico não-remunerado realizado por mulheres, seria menos valorizado socialmente. Nesse caso, a causalidade é estabelecida de forma a ressaltar quem realiza o trabaIho. No segundo, que ela atribui a Patricia Paperman (2013), a desvalorização seria um fator da vulnerabilidade e baixo reconhecimento social de quem precisa de cuidado, sobretudo idosos e deficientes. A causalidade, portanto, é estabelecida pelo destaque a quem recebe o cuidado. Aqui, me associo ao primeiro, sem excluir a possibilidade de que o segundo desempenhe um papel na desvalorização desse trabalho. Entendo que é na convergência entre convenções de gênero e ampliação da mercantilização das relações que se produz a desvalorização e precarização do trabalho remunerado doméstico e de cuidado. 
socialmente desvantajosa, a chance de que sejam definidas como problemas - e, ainda mais, como problemas políticos - se reduz. Embora, como dito anteriormente, não seja simples estabelecer a causalidade entre a divisão do trabalho e a participação dos indivíduos na política, podemos mobilizar a hipótese de que há mais do que coincidência no fato de que os indivíduos que exercem essas atividades são justamente aqueles que têm menor acesso aos espaços nos quais as decisões políticas ocorrem - e, como tal, menores condições de fazer valer suas experiências, codificando-nas como temas e demandas de caráter político. Esse raciocínio pode ser estendido também à produção do conhecimento. É possível mobilizar a hipótese de que quem participa da construção teórico-filosófica dos problemas da democracia tem mais chances de estar situado entre os que recebem cuidado mais frequente e intensamente do que entre os que o exercitam como cuidadores. Nos dois casos, no âmbito da prática política e no do pensamento político, essa situação converge para a prevalência de determinadas agendas, concepções e pressupostos.

Parece-me ser esse o contexto em que a independência dos homens como cidadãos e trabalhadores, assim como a dependência das mulheres quando estão na posição de cuidar de outras pessoas se definem como estereótipos (Brenner, 2000, p. 109), tipificando a situação concreta em que suas posições se definem por um jogo de luz e sombra que produz sentidos. Os primeiros, os homens como cidadãos e trabalhadores, são dependentes do trabalho de outras pessoas, em geral mulheres. Sem que alguém cozinhasse, mantivesse limpas suas roupas e, quando há filhos, cuidasse das crianças (ou estivesse disponível para levá-las e pegá-las na creche ou escola), para elencar apenas tarefas regulares bastante comuns, eles veriam afetada sua rotina de trabalho e reduzido seu tempo para recompor as energias do trabalho. Por outro lado, quando as mulheres se tornam dependentes, de programas sociais ou de homens que lhes são próximos, isso ocorre porque estão sendo responsabilizadas por tarefas cotidianas que vão ao encontro da dependência de outras pessoas. Mesmo essa dependência dos que são tomados como independentes não é algo que possa ser simplesmente eliminado. O problema está no fato de que as tarefas que garantem sua condição mais autônoma relativamente a quem é responsabilizado por elas sejam, ao mesmo tempo, invisibilizadas e alocadas de maneira desigual. 
O pensamento conservador defende o aperfeiçoamento da família e mais responsabilidade dos homens em nome da proteção às mulheres ${ }^{12}$. O liberalismo reformista, inclusive em abordagens feministas, defende que a mulher vulnerabilizada pela dependência receba assistência financeira por ter justificadamente falhado no teste da independência. As abordagens mais radicais no feminismo questionarão, diferentemente, as próprias noções de mérito e independência, assim como a visão da dependência como um desvio. Nos arranjos convencionais, os homens "são tão dependentes do trabalho não-remunerado das mulheres (incluindo seu trabalho emocional) quanto as mulheres são dependentes da renda dos homens" e o cuidado com as crianças é uma contribuição social e deveria ser assim reconhecido (Brenner, 2000, p. 104). É uma visão que contesta a escala de valorização das diferentes atividades e as formas de definição da independência e do mérito.

As alternativas consideradas para combater o empobrecimento das mulheres quando os casamentos terminam são um exemplo da mobilização de compreensões distintas dos papéis de gênero e da opressão a eles relacionada. No debate nos Estados Unidos, em que as disputas em torno das políticas de bem-estar social a partir dos anos 80 tornaram explícitas algumas dessas compreensões, há, tipicamente, argumentos favoráveis a políticas para a manutenção dos casamentos - mais casamento implicaria menos pobreza -, argumentos favoráveis à garantia de recursos para mulheres em condição de vulnerabilidade para que tenham condições de cuidar dos seus filhos - se os casamentos não são mantidos, o Estado entra, de certo modo, no lugar da renda do marido - e argumentos favoráveis a políticas para o compartilhamento do cuidado, como a oferta de creches e escolas públicas de qualidade em período integral, mudanças na legislação que avancem em direitos a flexibilidade na rotina de trabalho e a licenças para mães e pais com crianças pequenas ${ }^{13}$.

Nos dois primeiros casos, o papel convencional da mulher na esfera doméstica é reforçado ou reposto. Apenas no último se questiona não apenas esse papel, mas também a estruturação das relações de trabalho e de cuidado,

12 No Brasil, o exemplo mais atual é o Projeto de Lei 6.583, em defesa da "entidade familiar", proposto na Câmara dos Deputados em outubro de 2013. O rótulo "família" aparece nele como uma espécie de prêmio em que recursos, aprovação social e atenção do Estado vão para aqueles que se encaixam em uma forma de definição da vida conjugal, sexual, afetiva, parental.

13 Mapeio essas posições a partir de "The feminization of poverty", em Brenner (2000), "A genealogy of dependence", em Fraser (1997), e"Mothers, citizenship, and independence", em Young (1997). 
em seu aspecto de gênero, mas também em outro, que está estreitamente ligado a esse mas não se confunde inteiramente com ele, que é a privatização da vida familiar. A redefinição das responsabilidades individuais e coletivas depende de abordagens, e políticas, que ultrapassem o foco nos arranjos interpessoais e que sejam capazes de perceber de que modo as desigualdades de gênero se conectam a desigualdades de classe e de raça. É o que está presente na análise feita por Lena Lavinas (1996, p. 469) de que no combate à pobreza feminina dois grupos deveriam merecer especial atenção, as mulheres negras chefes de família e as mães solteiras. No primeiro caso, racismo e sexismo atuariam em conjunto; no segundo, os efeitos da maternidade e da maternagem na posição das mulheres no mercado de trabalho (rendimentos menores, por exemplo, como foi discutido aqui) se tornariam mais agudo por terem que dar conta sozinhas do cuidado e do sustento dos filhos.

A articulação entre dois níveis dessa crítica parece necessária: o enfrentamento das desigualdades correspondentes às formas atuais (privatizadas e mercantilizadas) do cuidado não pode prescindir de uma abordagem de gênero; o enfrentamento dessas mesmas desigualdades não se dará em um enfoque restrito ao gênero - mesmo que desconstrutivista -, uma vez que é na convergência entre gênero, classe e raça que elas se produzem.

A convivência entre a ampliação do leque de estilos de vida e a insegurança econômica de parte significativa da população é constitutiva das condições em que as relações de cuidado se estabelecem - nas palavras de Brenner (2010, p. 188), temos "oportunidades crescentes para a auto-expressão por meio de um amplo leque de identidades mercantilizadas" e "inseguranças e preocupações econômicas" também crescentes, derivadas da baixa proteção social. A tensão entre a lógica de mercado e a lógica da democracia está na base dessa convivência. Quando a primeira predomina, prevalece o que podemos definir como um enquadramento das relações e atividades humanas da perspectiva dos ganhos financeiros; a segunda, por sua vez, pode ser definida como a afirmação de valores e instituições nos quais prevaleceriam não apenas interesses plurais - colocando em questão o peso relativo dos agentes econômicos -, mas também a concepção de que os indivíduos são ao mesmo tempo atores e fins.

O quadro histórico mais amplo das formas atuais de organização da vida é aquele em que o trabalho remunerado é definido como fator primordial da socialização e da valorização do indivíduo, mas, em uma contradição perma- 
nente, é reduzido a um meio para a finalidade prioritária, que seria o consumo (Gorz, 2003 [1988]). Há uma continuidade entre o trabalhador-consumidor e a idealização da domesticidade - a racionalidade da competição, do oportunismo e da condescendência com os superiores hierárquicos no trabalho, organizado segundo as normas da eficiência econômica, teria como seu contraponto a vida privada confortável, opulenta e hedonista (Gorz, 2003 [1988], p. 43). A idealização da esfera doméstica serve mal às classes sociais menos privilegiadas, com ainda menos autonomia no seu cotidiano de trabalho e, sem dúvida, com menor remuneração e menores condições de alcançar os níveis de consumo que compensariam as formas de isolamento da família e a falta de tempo para o cultivo das relações. A lógica de mercado organiza a vida segundo valores quantificáveis, e não para que corresponda aos "valores relativos ao 'tempo de viver' da soberania existencial” (Gorz, 2003 [1988], p. 117).

Com o predomínio da lógica de mercado, impõe-se a exigência de que os indivíduos sejam "independentes", assumam responsabilidades e formas do cuidado com os outros e consigo que lhes são, no entanto, negadas cotidianamente como alternativas. A falta do cuidado adequado se transforma na comprovação da sua falta moral, em vez de ser lida como o resultado de um pacto social cruel e excludente.

Um caminho alternativo ao da mercantilização poderia ser assumir que "todos os membros adultos de uma sociedade têm alguma responsabilidade no suporte a todas as crianças" (Young, 1997, p. 111) e indivíduos vulneráveis. Além de políticas focadas no suporte aos indivíduos dependentes ${ }^{14}$, políticas de renda básica universal reduziriam a insegurança econômica das crianças, dos idosos e daqueles que são responsabilizados pelo cuidado dessas mesmas pessoas. A transposição da oposição entre trabalho remunerado e cuidado parece necessária para uma configuração mais justa das relações de gênero e de classe (Fraser, 1997, p. 61). O segundo permanece como barreira para o exercício do primeiro quando a responsabilização das mulheres pelo cuidado as impede de participar paritariamente da sociedade e quando os agentes de mercado, em vez de soluções públicas e coletivas, definem quem terá acesso ao cuidado ou apoio na tarefa de cuidar.

${ }_{14}$ O Beneficio de Prestação Continuada (BPC) é, no Brasil, um exemplo de programa de transferência de renda focado. É destinado a portadores de deficiências e a idosos com mais de 65 anos. Não há condicionalidades para o recebimento, mas é dirigido a pessoas que vivem em famílias com renda menor do que 1⁄4 do salário mínimo. Em 2012, atingia 3,6 milhões de pessoas (Medeiros, Britto e Soares, 2007). 
Se dependência e autonomia são referências conjuntas para a construção de relações mais igualitárias, a crítica à mercantilização parece ser, pelas razões antes elencadas, um dos esforços necessários. Mas a aposta na ampliação do suporte público não se apresenta livre de problemas. Algumas das ambivalências antes consideradas são válidas também aqui. $\mathrm{O}$ risco de que a ação do Estado se dê de forma que aprofunde as convenções de gênero que estão na base da responsabilização diferenciada tem sido, como dito anteriormente, alvo de críticas feministas ao Estado de bem-estar social. Nesse caso, são necessárias estratégias para promover a independência das mulheres como indivíduos e para dar suporte a elas como mães (Brenner, 2000, p. 118). Se a primeira dessas dimensões é deixada de lado, sua condição de cidadã pode ser comprometida - é o que ocorre quando sua condição de indivíduo é fundida a sua posição como mãe. Mas, por outro lado, quando a segunda é deixada de lado, a possibilidade de que as mulheres que são mães tenham acesso a oportunidades e chances de exercer efetivamente sua autonomia é comprometida - é o que ocorre quando se faz de conta que a responsabilização desigual não existe, legando às "famílias" a responsabilidade pelas crianças sem que se considere o fato de que isso implica a responsabilização das mulheres pelo cuidado, com os desdobramentos já discutidos.

É importante, assim, que as garantias aos direitos individuais não sejam confundidas com as políticas públicas de suporte às mulheres que desejarem ser mães e que essas não impliquem o apagamento das mulheres como indivíduos em nome da proteção às crianças, buscando alternativas para que uma e outra sejam consideradas concomitantemente.

Outra frente possível para essa crítica evoca o controle coletivo como algo distinto da ação do Estado. Ao falar sobre o sistema de saúde nos países da Europa Ocidental, André Gorz chama a atenção para o fato de que o Estado capitalista colabora para a definição dos problemas como individuais. Com isso, mesmo a ampliação da assistência e dos tratamentos mantém os indivíduos como consumidores menos ou mais atendidos, fortalecendo a ideologia do consumo. A realidade coletiva dos problemas de saúde seria, assim, ofuscada, reduzindo um enfoque que nos permitira a busca de alternativas para ampliarmos o controle coletivo sobre problemas que são coletivos e a "capacidade de cuidarmos de nós mesmos e termos uma vida saudável” (Gorz, 1985 [1983], p. 17). 
As condições materiais e simbólicas de quem cuida são, nas condições discutidas, frágeis. A posição de quem depende do cuidado de outras pessoas, em si vulnerável, tem sua vulnerabilidade ampliada quando sua dependência é uma peça na lógica de mercado. Ao mesmo tempo, o apoio público não significa, necessariamente, controle coletivo democrático. Este último é que permitiria regular as formas da responsabilidade estatal e coletiva para que não se desdobrem em ingerência indevida - as fronteiras entre uma coisa e outra teriam que ser democraticamente negociadas e definidas, o que remete a um tema de que não trato de fato aqui, o da privacidade. Permitiria também a construção de alternativas que não se apoiassem nas hierarquias existentes, como nos casos em que o apoio público reforça a manutenção das mulheres na posição de cuidadoras, sem uma preocupação com a vulnerabilidade social que está associada a essa posição.

\section{Conclusão}

No Brasil, as condições para cuidar e ser cuidado são deficientes dentro de casa e fora dela. Essa não é uma idiossincrasia, mas uma questão que se apresenta, ainda que em configurações distintas, na maior parte das sociedades democráticas hoje - daí a importância de se detectar a falta de discussões sobre esse tema na Ciência Política.

Há enormes desvantagens quando se assume o papel de cuidar de alguém em sociedades nas quais se nega ao cuidado valor e relevância, ou mesmo a sua definição como trabalho. Pela divisão sexual do trabalho doméstico, as mulheres são responsabilizadas, prioritariamente, por cuidar das crianças, dos idosos e dos enfermos, o que significa que seu tempo será concentrado nessas atividades ou terá de ser dividido entre o trabalho remunerado, o cuidado e o trabalho doméstico. Quanto menor é a possibilidade de ter apoio de instituições públicas - creches e atendimento médico-hospitalar ou doméstico adequado, por exemplo - maiores são as chances de quem cuida ter dificuldades para prover materialmente as próprias necessidades e as dos que lhe são próximos. A oferta de serviços privados alivia a condição das mulheres que têm recursos para contratá-los, mas aumenta o impacto dos arranjos privatizados e mercantilizados nas desigualdades de classe e de raça. Quem exerce cuidado não-remunerado, vê reduzidas não apenas suas condições para o exercício de trabalho remunerado, mas também seu acesso a tempo livre e oportunidades de autodesenvolvimento, estudo e pro- 
fissionalização. De modo mais amplo, quem cuida desenvolve uma atividade imprescindível, mas vê afetadas suas possibilidades de participar de maneira igualitária na sociedade. $\mathrm{O}$ cuidado remunerado padece da desvalorização social que decorre dessa configuração - em que as relações convencionais de gênero e a mercantilização definem as posições que os indivíduos têm entre o polo em que estão localizados aqueles que têm maiores chances de receber cuidado e o polo em que estão os que desempenham o trabalho de cuidar. Está, por isso, entre as atividades nas quais a remuneração é baixa e as condições de trabalho são precárias.

Os julgamentos morais que são feitos a partir da expectativa de que todos sejam igualmente capazes de "dar conta de si" e dos seus familiares impõem sanções e prejuízos a quem não corresponde a esse ideal. É um ideal orientado pelo mérito e pela competição, que suspende o fato de que as condições em que os indivíduos disputam uma posição ao sol são completamente distintas. Quando se presume, por exemplo, que os pais (em um discurso que, via de regra, atribui essa responsabilidade às mães) devem cuidar bem dos seus filhos, mas não há políticas adequadas para a conciliação entre trabalho remunerado e cuidado na vida doméstica, pune-se duplamente aqueles (ou, mais corretamente, aquelas) que não são, por razões estruturais, capazes de fazê-lo. Trata-se de um mito que funciona socialmente (Fineman, 2004), colaborando para que as desigualdades sejam justificadas e naturalizadas. As formas incontornáveis da dependência são permanentes no ciclo de vida dos indivíduos e fazem parte das relações que se estabelecem entre eles. Quando são ignoradas por normas e práticas sociais que teriam validade se todos fossem adultos, se todos fossem iguais na sua capacidade de trabalho e se todos tivessem um ponto de partida igual nos recursos para a construção das suas vidas, não se definem condições adequadas para o cuidado. O que procurei mostrar aqui é que a ausência dessas condições, assim como a busca de soluções que repousem sobre a subordinação de algumas pessoas, não é compatível com a justiça.

Entre as soluções que procurei mostrar que são inadequadas está a manutenção da divisão sexual do trabalho como fundamento de políticas para o cuidado. Não é uma direção desejável quando se busca um caminho para as questões envolvidas no cuidado que seja também o da igualdade de gênero. Mas, além de não ser uma solução desejável, também não é mais, se é que foi algum dia, factível. Com mais mulheres no mercado de trabalho e com formas de organização das relações de trabalho que exigem a ausência das 
mulheres do espaço doméstico, a industrialização e socialização do trabalho doméstico se torna "uma necessidade social objetiva" (Brenner, 2010, p. 224).

Ao mesmo tempo, procurei expor os limites da mercantilização, que pode ser a solução para a posição desigual de algumas mulheres, mas aprofunda desigualdades e injustiças num prisma em que convergem gênero, classe e raça. Por isso, um dos desafios quando se entende que a configuração convencional de gênero não é uma resposta adequada e mesmo possível é imaginar políticas para a promoção de relações de cuidado fortalecidas, baseadas em valores solidários, e não na lógica de mercado. Aqui, os constrangimentos que a realidade impõe à imaginação política se desdobram em uma acomodação pouco útil à melhoria das condições de vida. Daí a importância de que essas questões sejam consideradas nos debates e nos esforços para o aprofundamento da democracia, no âmbito teórico e no da prática política. A centralidade do cuidado é fundamental para abordagens da democracia que ultrapassem a igualdade formal, em direção a uma compreensão alargada dos mecanismos de reprodução de vantagens e desvantagens para os indivíduos e grupos sociais.

A atribuição das responsabilidades, assim como as formas possíveis da igualdade, varia ao longo da vida. Por isso, "quando as pessoas são jovens e se encontram em um estado de dependência, elas precisam de acesso igual ao cuidado adequado para que possam crescer e se transformar em adultos plenamente capazes" (Tronto, 2013, p. 108). Quando adultas, devem ter direito de se expressar de maneira independente e como iguais, o que faz com que seja necessário adotar mecanismos institucionais que garantam que não serão silenciadas. Para tanto, é preciso também construir afirmativamente as condições para essa vocalização, assegurando práticas e arranjos, na vida doméstica e no trabalho, que permitam que os indivíduos tenham tempo e recursos para tomar parte na vida política, no debate público e em esforços coletivos que lhes pareçam relevantes. E, em uma terceira condição para a igualdade, "quando as pessoas estão doentes, idosas, ou incapacitadas, é preciso que existam arranjos institucionais que assegurem que suas vozes também serão ouvidas" (Tronto, 2013, p. 109).

A ampliação da responsabilidade social pelo cuidado seria, assim, construída em um processo democrático de que aqueles que estão na posição de dependentes e aqueles que dispendem cuidado tomariam parte. Em vez de privatismo e isolamento, teríamos a chance de encontrar alternativas sociais para que as necessidades de cuidado que todos temos ao longo da vida se- 
jam adequadamente nutridas. Não é necessário romper com a ideia de que temos responsabilidades especiais - como aquelas que os pais, biológicos ou não, têm em relação às crianças - para avançar no sentido de construir instituições e mecanismos de apoio que garantam que a integridade e o bem-estar, sobretudo dos mais vulneráveis, não estejam sujeitos à sorte ou à lógica de mercado.

\section{Bibliografia}

ANDERSON, Elizabeth (1999). "What is the point of equality?”. Ethics, vol. 109, n. 2, pp. 287-337.

ARAÚJO, Clara e Céli SCALON (2006). "Gênero e a distância entre a intenção e o gesto”. Revista Brasileira de Ciências Sociais, vol. 21, n. 62, pp. 45-68. BENHABIB, Seyla (1987). "The generalized and the concrete other: the Kohlberg-Gilligan controversy and feminist theory”, em BENHABIB, S. \& CORNELL, D. (eds.). Feminism as critique. Minneapolis: University of Minnesota Press.

BRENNER, Johanna (2000). Women and the politics of class. New York: Monthly Review Press.

BIROLI, Flávia (2013). Autonomia e desigualdades de gênero: contribuições do feminismo para a crítica democrática. Niterói: Eduff; Vinhedo: Horizonte. BIROLI, Flávia (2014). Família: novos conceitos. São Paulo: Editora da Fundação Perseu Abramo.

DAVIS, Angela Y. (1983 [1981]). Women, race, \& class. New York: Vintage. DELPHY, Christine e Diana LEONARD (2004 [1992]). Familiar exploitation: a new analysis on marriage in contemporary western societies. Cambridge: Polity Press.

DWORKIN, Ronald (2005 [2000]). Virtude soberana. São Paulo: Martins Fontes.

FINEMAN, Martha Albertson (2004). The autonomy myth: a theory of dependency. New York: The New Press; Cambridge: Polity Press.

FRASER, Nancy (1997). Justice interruptus: critical reflections on the "postsocialist" condition. New York: Routledge.

GILLIGAN, Carol (1982). In a different voice: psychological theory and women's development. Cambridge: Harvard University Press.

GORZ, André (1985 [1983]). Paths to paradise: on the liberation from work. London: Pluto Press. 
GORZ, André (2003). Metamorfoses do trabalho: crítica da razão econômica. São Paulo: Annablume.

GUYER, Paul (2003). "Kant on the theory and practice of autonomy", em PAUL, E. F.; MILLER Jr., F. D. \& PAUL, J. (eds.). Autonomy. Cambridge: Cambridge University Press; pp. 70-98.

HIRATA, Helena (2014). "Gênero, classe e raça: interseccionalidade e consubstancialidade das relações sociais”. Tempo social, vol. 26, n. 1, pp. 61-73.

HIRATA, Helena e Nadya Araujo GUIMARÃES (orgs.) (2012). Cuidado e cuidadoras: as várias faces do trabalho do care. São Paulo: Atlas.

HOCHSCHILD, Arlie Russell 2003 [1983]. The managed heart: commercialization of human feeling. Berkeley: University of California Press.

HOOKS, Bell (1984). Feminist theory: from margin to center. 2.ed. New York: South End Press.

IBGE (2013). Pesquisa Nacional por Amostra de Domicílios 2012: síntese de indicadores. Rio de Janeiro: IBGE.

IPEA (2011). Retrato das desigualdades de gênero e raça. 4.ed. Brasília: IPEA. KOLLONTAI, Alexandra (1977). "Theses on communist morality in the sphere of marital relations", em Selected writings. New York: W. W. Norton.

LAVINAS, Lena (1996). "As mulheres no universo da pobreza: o caso brasileiro". Revista Estudos Feministas, ano 4, n. 2 , pp. 464-479.

McCLUSKEY, Martha T. (2003). "Efficiency and social citizenship: challenging the neoliberal attack on the welfare state". Indiana Law Journal, n. 78, vol. 2, pp. 783-876.

MEDEIROS, Marcelo; Tatiana BRITTO e Fábio SOARES (2007). "Programas focalizados de transferência de renda no Brasil: contribuições para o debate". Texto para discussão n. 1283. Brasília: Ipea.

MILL, John Stuart (2008 [1859]). On liberty. Sioux Falls: New Vision Publications.

MIGUEL, Luis Felipe (2014). Democracia e representação: territórios em disputa. São Paulo: Editora Unesp.

MIGUEL, Luis Felipe e Flávia BIROLI (2011). Caleidoscópio convexo: mulheres, política e mídia. São Paulo: Editora Unesp.

MIGUEL, Luis Felipe e Flávia BIROLI (2014). Feminismo e política: uma introdução. São Paulo: Boitempo. 
MOLINIER, Pascale (2014). "Cuidado, interseccionalidade e feminismo". Tempo social, vol. 26, n. 1, pp. 17-33.

OKIN, Susan Moller (1989). Justice, Gender, and the Family. New York: Basic Books.

PATEMAN, Carole (1988). The sexual contract. Stanford: Stanford University Press.

PINTO, Celi Regina Jardim (2010). “Feminismo, história e poder”. Revista de Sociologia e Política, vol. 18, n. 36, pp. 15-23.

RAWLS, John (1971). A theory of justice. Cambridge: Harvard University Press.

SANDEL, Michael J. (1998 [1982]). Liberalism and the limits of justice. Cambridge: Cambridge University Press.

SARTI, Cynthia (2011). A família como espelho: um estudo sobre a moral dos pobres. 7.ed. São Paulo: Cortez.

SARTI, Rafaella (2006). "Domestic service: past and present in Southern and Northern Europe”. Gender \& History, vol. 18, n. 2; pp. 222-245.

SCHEFFLER, Samuel (2003). "What is egalitarianism?" Philosophy \& Public Affairs, vol. 31, n. 1, pp. 5-39.

SCHWENKEN, Helen (2011). "Mobilisation des travailleuses domestiques migrantes: de la cuisine à l'Organization internationale du travail”. Cahiers du genre, vol. 2, n. 51, pp. 113-133.

SCHWENKEN, Helen (2005). "The challenges of framing women migrants' rights in the European Union”. Revue Européenne des migrations internationals, vol. 21, n. 1, pp. 177-194.

SORJ, Bila (2013). "Arenas do cuidado nas interseções entre gênero e classe social no Brasil". Cadernos de Pesquisa, vol. 43, n. 149, pp. 478-91.

SUNSTEIN, Cass R. (2009 [1991]). "Preferências e política”. Revista Brasileira de Ciência Política, n. 1, pp. 219-254.

TRONTO, Joan C. (1987). "Beyond gender difference to a theory of care". Signs, vol. 12, n. 4, pp. 644-663.

TRONTO, Joan C. (2013). Caring democracy: markets, equality, and justice. New York: New York University Press.

VITA, Álvaro de (2011). "Liberalismo, justiça social e responsabilidade individual”. Dados, vol. 54, n. 4, pp. 569-608.

YOUNG, Iris Marion (1997). Intersecting voices: dilemmas of gender, political philosophy, and policy. Princeton: Princeton University Press. 
YOUNG, Iris Marion (2006). “Taking the basic structure seriously”. Perspectives on Politics, vol. 4, n. 1, pp. 91-97.

YOUNG, Iris Marion (2011). Responsibility for justice. Oxford: Oxford University Press.

WALBY, Sylvia (1990). Theorizing patriarchy. Oxford: Basil Blackwell.

\section{Resumo}

As relações de cuidado são parte do cotidiano das pessoas e um fator na produção de desigualdades nas democracias, embora sejam pouco tematizadas na Ciência Política e praticamente ausentes na Ciência Política brasileira. A configuração dessas relações é determinante das possibilidades de acesso a recursos e à participação política, assim como para a garantia de integridade física e psíquica para os indivíduos. Embora a responsabilização das mulheres pelo trabalho doméstico, em que incluo o trabalho de cuidar de outras pessoas, sobretudo das mais vulneráveis, seja um aspecto central das assimetrias existentes, as formas mercantilizadas do cuidado são um elemento importante também nas desigualdades de classe. $\mathrm{O}$ artigo propõe um deslocamento da noção liberal de responsabilidade em direção ao problema da responsabilização desigual. Com isso, analisa a divisão sexual do trabalho e as diferentes formas de dependência que são parte do cotidiano, colocando o cuidado como questão fundamental para a democracia e a justiça.

Palavras-chave: cuidado, democracia, trabalho, desigualdades, gênero, classe social.

\section{Abstract}

Caring relationships are part of people's daily lives and a factor generating inequalities in democracies, although they are scarcely discussed in Political Science and virtually absent from Brazilian Political Science. The configuration of those relationships is critical for the possibilities of access to resources and political participation, as well as for assuring individuals' physical and psychological integrity. Even though women's responsibility for housework - in which I include caring for others, especially the most vulnerable - is a central aspect in existing asymmetries, commodified forms of care are also an important element in class inequalities. This article proposes a shift from the liberal notion of responsibility towards the issue of unequal accountability. It analyzes sexual division of labor and the different forms of dependence that are part of everyday life, placing care as a fundamental issue for democracy and justice.

Keywords: care, democracy, labor, inequalities, gender, social class

Recebido em 31 de maio de 2015.

Aprovado em 17 de agosto de 2015. 